\title{
Late pericardial tamponade and coronary arteriovenous fistula after trauma
}

\author{
ROBIN MARTIN, ANDREW MITCHELL, NAZIR DHALLA \\ From the Department of Cardiology and Cardiothoracic Surgery, Harefield Hospital, Middlesex
}

SUMMARY A 48 year old man presented with cardiac tamponade six weeks after an apparently minor penetrating chest injury. Thoracotomy showed a haemopericardium with no actively bleeding vessel. Re-investigation eleven months later, prompted by persistent chest pain, showed the presence of a fistula between the second diagonal of the left anterior descending coronary artery and a cardiac vein.

\section{Case report}

A 48 year old man presented to another hospital having collapsed at home. He had been experiencing infrequent episodes of central and left sided anterior chest pain at rest for two years. In the week before admission the pain increased in frequency and severity and this culminated in a prolonged episode associated with loss of consciousness. There was no history of hypertension or serious illness. When he was first examined he was semiconscious, pale, and cyanosed (pulse of 120 beats per minute, blood pressure of $80 / 50 \mathrm{~mm} \mathrm{Hg}$ ). Venous pressure was raised and a fourth heart sound was heard. He was transferred to our hospital with a clinical diagnosis of possible aortic dissection and his clinical condition was unchanged on arrival at Harefield Hospital. The central venous pressure was $19 \mathrm{~cm}$ of water above the mid-axillary line and all peripheral arterial pulses were present and of equal strength. He had a small puncture mark on the anterior surface of the chest in the fifth intercostal space $2 \mathrm{~cm}$ medial to the mid-clavicular line.

An electrocardiogram showed sinus rhythm with flattening of the anterior $T$ wave. A chest radiograph showed moderate cardiomegaly and a small left pleural effusion. A cross sectional echocardiogram showed a pericardial effusion with no features to suggest cardiac tamponade, but cardiac catheterisation showed cardiac tamponade. The right and left ventricular minimum diastolic pressures were $10 \mathrm{~mm} \mathrm{Hg}$ with an end diastolic pressure of 18

Requests for reprints to Dr R P Martin, Department of Cardiology, Harefield Hospital, Harefield, Middlesex UB9 6JH. $\mathrm{mm} \mathrm{Hg}$ and had a characteristic dip and plateau pattern. Pulmonary and aortic angiography excluded major embolism and dissection. Coronary angio- $\overrightarrow{0}$ grams were not obtained at this examination.

Pure blood was obtained by pericardial aspiration and at left thoracotomy a small haematoma on the anterior surface of the left ventricle and haemopericardium were noted with no evidence of active bleeding. No other abnormality was found. An operation was performed to produce a pericardial window.

After operation he gave a clear history of a penetrating chest injury. Six weeks before admission while he was using a circular saw to cut floor boards he fractured a steel nail and a $3 \mathrm{~cm}$ fragment pene- $\vec{\Phi}$ trated his chest. He removed the fragment and $\stackrel{\rho}{7}$ suffered some sharp chest pain but was soon able to continue working.

At follow up he continued to have episodic left $\delta$ sided chest pains at rest. The only new finding on examination was a quiet apical ejection murmur. 음 Cardiac catheterisation excluded recurrent tam- $D$ ponade and constriction, but left ventricular angiography showed mild apical hypokinesia.

Selective coronary arteriograms showed two \% fistulous connections, one between the second diag- $N$ 'onal branch' of the left anterior descending coro- $N$ nary artery and a branch of the great cardiac vein (Fig. 1) and a second filling a small vessel within theo lung (Fig. 2). Exercise testing and thallium scanning $\overparen{\complement}$ excluded cardiac ischaemia but did identify a small? resting anterolateral perfusion defect.

\section{Discussion}

This case illustrates the combination of two rareo 216 


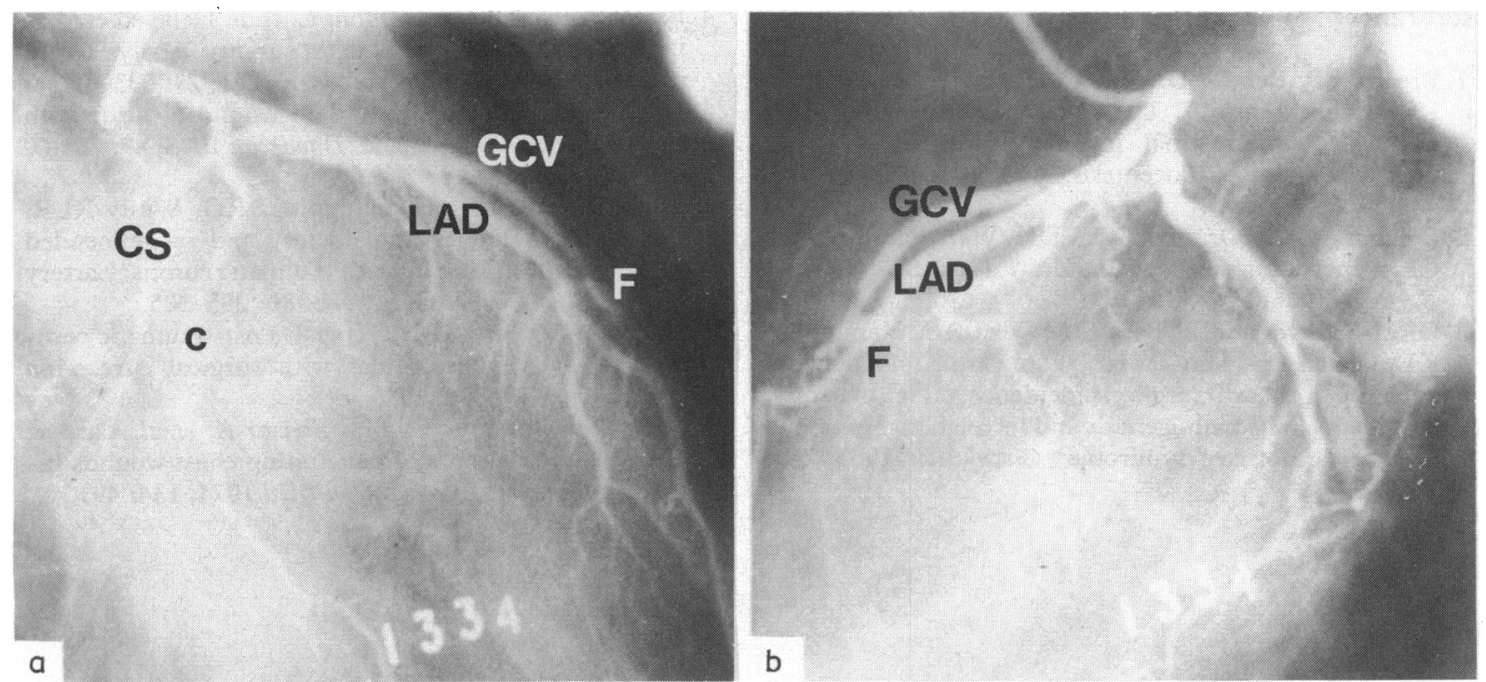

Fig. 1 Left coronary arteriograms (a) in the right anterior oblique projection and $(b)$ in the left anterior oblique projection. The fistula $(F)$ can be seen arising from the second diagonal branch of the left anterior descending coronary artery (LAD) with early opacification of the great cardiac vein (GCV) and coronary sinus (CS). C, circumflex branch.

complications of penetrating injury of the chest. Pericardial tamponade is a relatively common feature of such injuries but usually presents very early after trauma. ${ }^{12}$ Delayed tamponade is much less frequent and has usually been described after surgery $^{34}$ and rarely after trauma. ${ }^{5}$ The latent period of six weeks before the onset of tamponade is longer than previously described after trauma but similar to that found after operation (usually as part

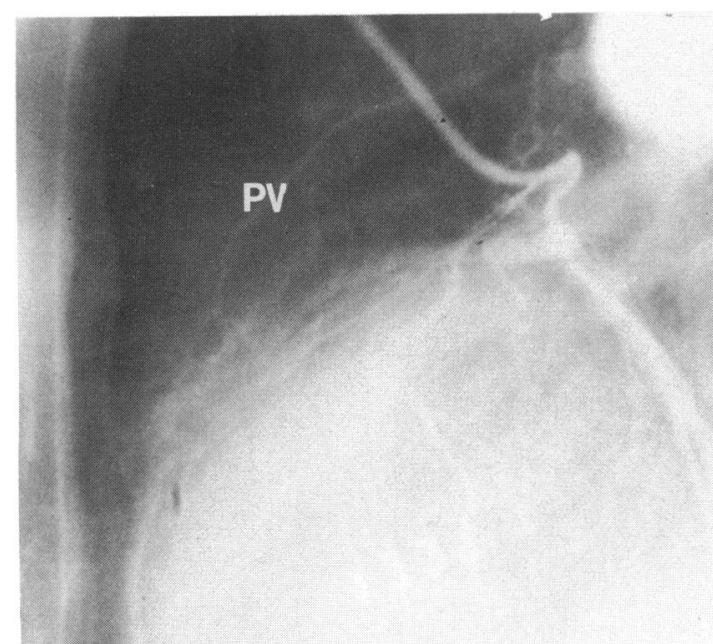

Fig. 2 Left coronary arteriogram in the left anterior oblique projection showing filling of a pulmonary vessel (PV). of the postpericardiotomy syndrome). The second feature in this case is the development of a coronary arteriovenous fistula. Fistula formation is rare after trauma and generally affects a coronary vessel and right ventricle or right atrium. ${ }^{6}$ We found only two published reports of coronary arteriovenous fistulas. ${ }^{78}$ Since selective coronary angiography was not performed before the exploration of the pericardium it is not possible to define the precise relation between the development of the fistula and intrapericardial bleeding. The development of a coronary artery to intrapulmonary fistula may follow the removal of pericardium in the region of the anterior descending artery, but in this case the fistula is more likely be related to the original injury, in view of the haematoma observed at thoracotomy.

It has been suggested that coronary arteriovenous fistulas should be closed surgically. ${ }^{6}$ In our case the degree of shunting is small, the chest pain is not typically cardiac, and there is no objective evidence of exercise induced ischaemia. A coronary steal could theoretically arise, but this appeared unlikely because of the degree of shunting observed angiographically. Consequently the fistula has not been closed at this stage; there has been no evidence of further cardiac complications or bleeding during 15 months of follow up.

We thank Mr Alun Rees for performing the thoracotomy and for allowing us to report on this patient. 


\section{References}

1 Breaux EP, Benton Dupont J Jr, Albert HM, Bryant LR, Schechter FG. Cardiac tamponade following penetrating mediastinal injuries: improved survival with early pericardiocentesis. $\mathcal{F}$ Trauma 1979; 19: 461-6.

2 Symbas PN, Di Orio D, Tyras DH, Ware RE, Hatcher CR. Penetrating cardiac wounds. $\mathcal{f}$ Thorac Cardiovasc Surg 1973; 66: 526-32.

3 Ofori-Krakye SK, Tyberg TI, Geha AS, Hammond GL, Cohen LS, Langou RA. Late cardiac tamponade after open heart surgery: incidence, role of anticoagulants in its pathogenesis and its relationship to the postpericardiotomy syndrome. Circulation 1981; 63: 1323-8.
4 Bartolotti U, Livi U, Frugoni C, et al. Delayed cardiac tamponade following open heart surgery. Analysis of 12 patients. Thorac Cardiovasc Surg 1981; 29: 233-6.

5 Lempinen M, Silvonen E. Stab wound of heart with delayed cardiac tamponade. Duodecim 1973; 89: 265-7. (English Abstract.)

6 Lowe JE, Adams DH, Cummings RG, Wesly RLR, Phillips HR. The natural history and recommended management of patients with traumatic coronary artery fistulas. Ann Thorac Surg 1983; 36: 295-305.

7 Sarot IA, Schecter DC, Weber J. Post-traumatic coronary arterio-venous fistulas with surgical cure. $A n n$ Thorac Surg 1968; 6: 172.

8 Heller RF, Rahimtoola SH. Ehsani A, et al. Cardiac complications: results of penetrating chest wounds involving the heart. Arch Intern Med 1974; 134: 491. 